\title{
ARISTOTELIS
}

$\begin{array}{lllllll}\mathbf{P} & \mathbf{H} & \mathbf{Y} & \mathbf{S} & \mathbf{I} & \mathbf{C} & \mathbf{A}\end{array}$

EX RECENSIONE

\section{IMMANUELIS BEKKERI}

SEORSIM EDITA.

\section{BEROLINI}

TYPIS ET IMPENSIS GE. REIMERI

A. 1843. 
